\title{
SPECIAL ISSUE: PERSPECTIVES ON MUSIC EDUCATION
}

\section{Editorial}

Music education is an eclectic field of study, and those concerned with questions of musical learning and teaching draw upon a variety of disciplines including psychology, sociology, history, philosophy, ethnomusicology, and music therapy. For this Special Issue, we have asked leading scholars within these disciplines to share insights on how their research area might contribute to a greater understanding of the learning and teaching of music. Our aim and theirs is to communicate recent developments in the disciplines to music educators, and hopefully to stimulate in the pages of BJME a dialogue with colleagues in related fields of interest.

It has been a pleasure and a privilege as editors to invite papers from authors whose work we have previously found to be stimulating and engaging. The six papers that follow reflect their authors' active and internationally respected status as researchers, bringing to the journal detailed and critical evaluations of their own disciplines, and some fresh perspectives on music education. The authors act as guides in what may be unfamiliar territory, pointing out the landmarks of their own discipline, and the many valuable points of connection with music education research and practice.

Within the papers there are points of overlap and comparison which highlight the complexity of debate in current music education research, as international differences are set alongside disciplinary boundaries to emphasise the need for broad perspectives in understanding musical teaching and learning. Questions are raised concerning the roles that music can play in the lives of young people, the place that it holds in the curriculum, and the contested nature of musical knowledge and processes.

Marie McCarthy argues cogently for the centrality of the historical perspective, whilst acknowledging that music education history remains marginalised and often ignored. She encourages music educators to seek a greater historical understanding, reassessing our understanding of the ordering of historical time and questioning the objectivity of memory. Further ideas on the construction of musical knowledge are explored by Jonathan Stock from an ethnomusicological point of view, as he tackles notions of identity, improvisation, power and status, transmission, and ability. Stock highlights not only the overlaps between ethnomusicology and music education, but also the points of difference, particularly in research methods, that may have led to misunderstandings and oversimplifications in the past. He urges us towards a 'heterogeneous multidisciplinarity' rather than a 'facile interdisciplinarity', so underlining one of the aims of this Special Issue and presenting a challenging call for future research.

Reflecting on the explosion of research in social psychology since the mid-1980s, Hargreaves, Marshall and North give a lucid account of the levels of social influence which affect musical development: the individual, the interpersonal, the institutional and the cultural. All too often our thinking in music education remains stuck at the institutional level, but here we are invited to look beyond at the broader questions of what music education is for. Tia DeNora, too, argues for the emotional and social power of music, asking us to recognise the impact of social and cultural constructions on our thinking about music education and to respond to new ways of thinking beyond disciplinary boundaries. 
Leslie Bunt offers further challenges to music educators, specifically in their collaboration with music therapists. He sees this relationship as complementary, with therapists and educators working towards the common purpose of facilitating the development of the whole child. Finally, Estelle Jorgensen gives us a North American perspective on what philosophy can bring to music education, and leaves us with some fundamental and perhaps uncomfortable questions about talent, inclusion and musical provision.

Our contributors to this Special Issue ask engaging questions and provide some stimulating and original answers. The National Curriculum is mentioned hardly at all, and this is a vivid illustration of how often our thinking in music education is constrained by policy decisions which obscure the more important debates to be had. We hope you enjoy the broader perspectives offered here, and will respond through your own research and practice by thinking further about the crossing of disciplinary boundaries, with all the opportunities and challenges that can bring to music education.

\section{Dr Gerry Farrell, 1951-2003}

It was with great sadness that we learned of the death of Dr Gerry Farrell on Friday 4 April. Gerry was a newly appointed member of our Editorial Board, and we were looking forward immensely to this collaboration. His association with the journal as a writer was longstanding, from his paper 'Teaching Indian Music in the West: Problems, Approaches and Possibilities' (1986) to his review of Sound Identities (2001). As a skilled sitarist, an eminent authority on Indian music, and an inspirational teacher, he was highly influential in music education in the UK, and particularly keen to bring a greater international dimension to the curriculum. His book Indian Music in Education (1990) and his classroom resource Music of India (1994) demonstrate his combination of scholarship and practicality. His death will be mourned throughout the international music education community.

GORDON COX STEPHANIE PITTS 